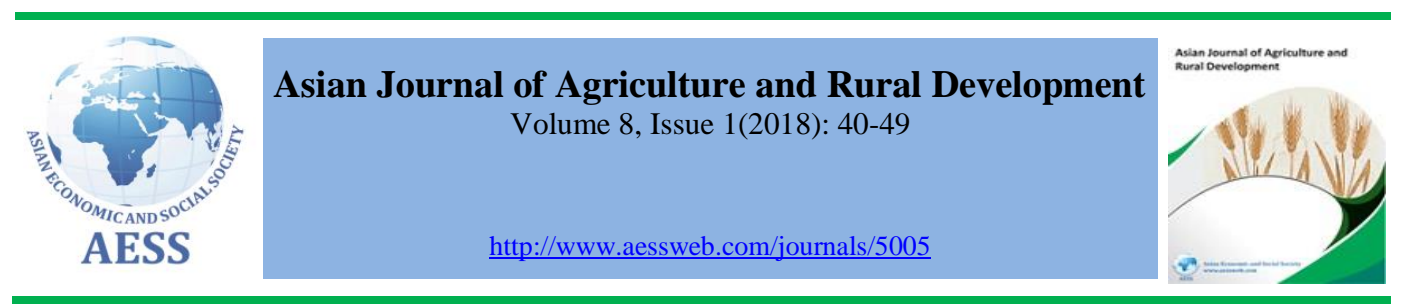

\title{
NUTRITION PROMOTION AND COLLECTIVE VEGETABLE GARDENING BY ADOLESCENT GIRLS: FEASIBILITY ASSESSMENT FROM A PILOT IN AFGHANISTAN
}

\author{
(ID) Md. Abdul \\ $\operatorname{Alim}^{\mathrm{a}}$ \\ M. Anowar \\ Hossain $^{b}$
}

a Research Fellow and Head, Independent Evaluation and Research Cell, International Institute of Social Studies (ISS), The Netherlands $\triangle$ alimabdu@gmail.com (Corresponding Author)

b Country Representative, BRAC Afghanistan, Kart-e-Parwan, Kabul, Afghanistan

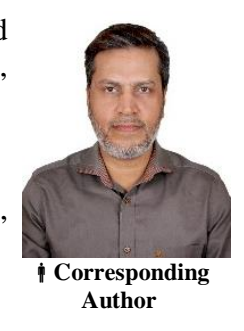

\section{ARTICLE HISTORY:}

Received: 26-Jul-2018

Accepted: 19-Sep-2018

Online Available: 04-Oct2018

\section{Keywords:}

Adolescent girls,

Feasibility,

Vegetable gardening,

Afghanistan,

South Asia

\begin{abstract}
This study aimed to assess the feasibility of collective vegetable gardening into an existing development programme for adolescent girls as a means of improving awareness about health and nutrition and increasing vegetable consumption in Afghanistan. A one and half year pilot study tested the feasibility of layering an intervention that combined agricultural training and input support in Kabul, Parwan and Kapisa regions on an adolescent programme implemented by a non-government organisation. The study included 400 adolescent girls for survey and qualitative tools to understand the local context of adolescent girls' participation in vegetable cultivation. The assessment demonstrates the evidence that despite of the challenging situation and traditional culture in Afghanistan the pilot had successfully engaged almost all of the adolescent girls in collective vegetables cultivation by making them aware about health, nutrition and the usefulness of vegetables consumption while the bad effects of not intake those. And the cultivation proved itself financially viable and very much effective for the community though there were little challenges. The pilot would be feasible and scalable to address the malnutrition and girls' marginalization if those challenges were taken into consideration carefully.
\end{abstract}

\section{Contribution/ Originality}

Afghanistan is the war savaged and landlocked country where, among other challenges, women especially adolescent girls are culturally, politically and economically marginalized. This study demonstrates the pilot project of vegetables cultivation being implemented by school dropped out adolescent girls could be scaled up and sustained to address the malnutrition and might reduce their marginalization steadily.

DOI: 10.18488/journal.1005/2018.8.1/1005.1.40.49

ISSN (P): 2304-1455/ISSN (E):2224-4433

How to cite: Md. Abdul Alim and M. Anowar Hossain (2018). Nutrition promotion and collective vegetable gardening by adolescent girls: feasibility assessment from a pilot in Afghanistan. Asian Journal of Agriculture and Rural Development, 8(1), 40-49.

(C) 2018 Asian Economic and Social Society. All rights reserved. 


\section{INTRODUCTION}

Among many challenges that include over the decades of conflicts, gender conservatism, failure of delivering the public services to the most of the citizens and continued worse economic condition in particular that Afghanistan faces in their socio-economic development, malnutrition is one of the major ones. Despite some recent progresses, the country has still very high malnutrition rates. The Afghanistan National Nutrition Survey (NNS) (2013) reveals high stunting (40\%) and underweight (25\%) rates among under-5 children. Adolescents (10-19 years) are also found malnourished revealing with $8 \%$ of them being thin, meaning that the situation is also not much better for adult population. Micronutrient deficiencies are even more widespread in this country (Ibid). For example, $40 \%$ of the women of reproductive age and $45 \%$ of the 6-59 months old children are anaemic. Vitamin-A deficiency is also common 6-59 months old children (50.4\%). Zinc deficiency is found among both women and children, with the prevalence rates of $23 \%$ and $15 \%$ respectively. Similarly, Iodine deficiency was fairly common among both women of reproductive age and children 7-12 years of age, with a prevalence of $41 \%$ and $30 \%$ respectively.

Among other reasons, lack of access to food is responsible for malnutrition. National Risk and Vulnerability Assessment (NRVA) (2011/2012) shows 31\% of households across the country do not meet their daily caloric needs $(2,100 \mathrm{kcal} /$ person/day), and $35 \%$ of households had inadequate food consumption. Besides, there is poor dietary diversity that contributes to micronutrient deficiencies. There is very low levels of consumptions of vegetables, a major source of the micronutrients, with only $50 \%$ of the households consuming such food in this country (LANSA, 2017). There is also a clear difference in vegetables consumption by wealth categories ( $63 \%$ vs. $31 \%$ for the richest vs. poorest quintiles) suggesting access as one of the constraints to low level of vegetable consumption.

Food habit and low engagement of women in agriculture are among the other commonly cited constraints for low vegetable consumption. Other factors include food and nutrition insecurity as a result of climate change, water scarcity and poor access to social services. These factors are compounded by traditional and cultural beliefs, women's low social status, adverse climatic conditions, and poor infrastructure (Ibid). Besides, the immediate causes are lack of knowledge on appropriate nutrition practices, inadequate intake of nutritious food, and a high disease burden which perpetuate the problem.

Agriculture and nutrition are closely linked with each other but Afghan women and girls are highly disempowered - their involvement in agricultural activities are very limited; they have serious lack of access to credit, inputs, information and training; they lack ownership and access to productive assets; they have high time poverty due to domestic and care activities; and they face discrimination in the labour market (Holmes and Jones, 2009). Moreover, the policy and programming do not adequately recognise the gendered experiences of poverty and vulnerability in the country. Therefore, this has tremendously impacted on the vegetable consumption.

Increasing vegetable consumption as a means of improving micronutrient deficiency and overall nutritional status of the adolescent girls, therefore, is an important policy priority for the country. In a literature review, Ruel and Alderman (2013) postulates that the most promising avenue of addressing under-nutrition needs a cohesive approach that combines training and sensitisation of nutrition with targeted agricultural interventions to create access to nutritious food items. Sen et al. (2010) make very similar argument that achieving progress on nutrition requires implementation of nutrition sensitive agricultural interventions in addition to the existing nutrition specific programmes by leveraging on various ongoing economic and social empowerment programmes. Their suggestion of leveraging on ongoing programmes is of particular importance to make the progresses prompt and meaningful with available resources. Large scale impacts can only be secured with adequate evidences on operational feasibility and effectiveness of different innovations. 
Given this context, BRAC (earlier known as Bangladesh Rural Advancement Committee) in Afghanistan tested the feasibility of an intervention that combined nutritional training and collective vegetables gardening by leveraging on an existing programme for adolescent girls. This paper assessed the feasibility and scalability of the intervention by looking into the changes in knowledge of the adolescent girls related to nutrition and health indicators, perception of girls' collective vegetables cultivation followed by consumptions to contribute to reducing malnutrition as well as raising their voices.

\section{MATERIALS AND METHODS}

The research design was a randomized control trial with baseline and endline survey by combining both qualitative and quantitative methods.

\subsection{Study area and pilot intervention}

BRAC Afghanistan established Adolescent Reading Centres (ARCs) in 2016, each consisted of 25 adolescent girls aged 15 to 25 years, to impart life skills and learning opportunities for school dropped out adolescent girls in remote village. Out of 40 ARCs 16 were randomly selected from Kabul, Kapisa and Parwan regions based on the criteria that included the security of the areas, easy communication from the central office, prospect of nutrition sensitive agricultural activities by the adolescent girls, the high level of malnutrition and micro-nutrient deficiency of women particularly for adolescent girls and the low level of dietary diversity. Out of 16 ARCs 6 ARCs each from Kabul and Parwan and 4 from Kapisa were selected for baseline study in March, 2016 while endline survey was conducted in March 2017. As a treatment ARC 3 each from Kabul and Parwan and 2 from Kapisa were selected and similar number of ARCs were selected as control in those regions but in different districts.

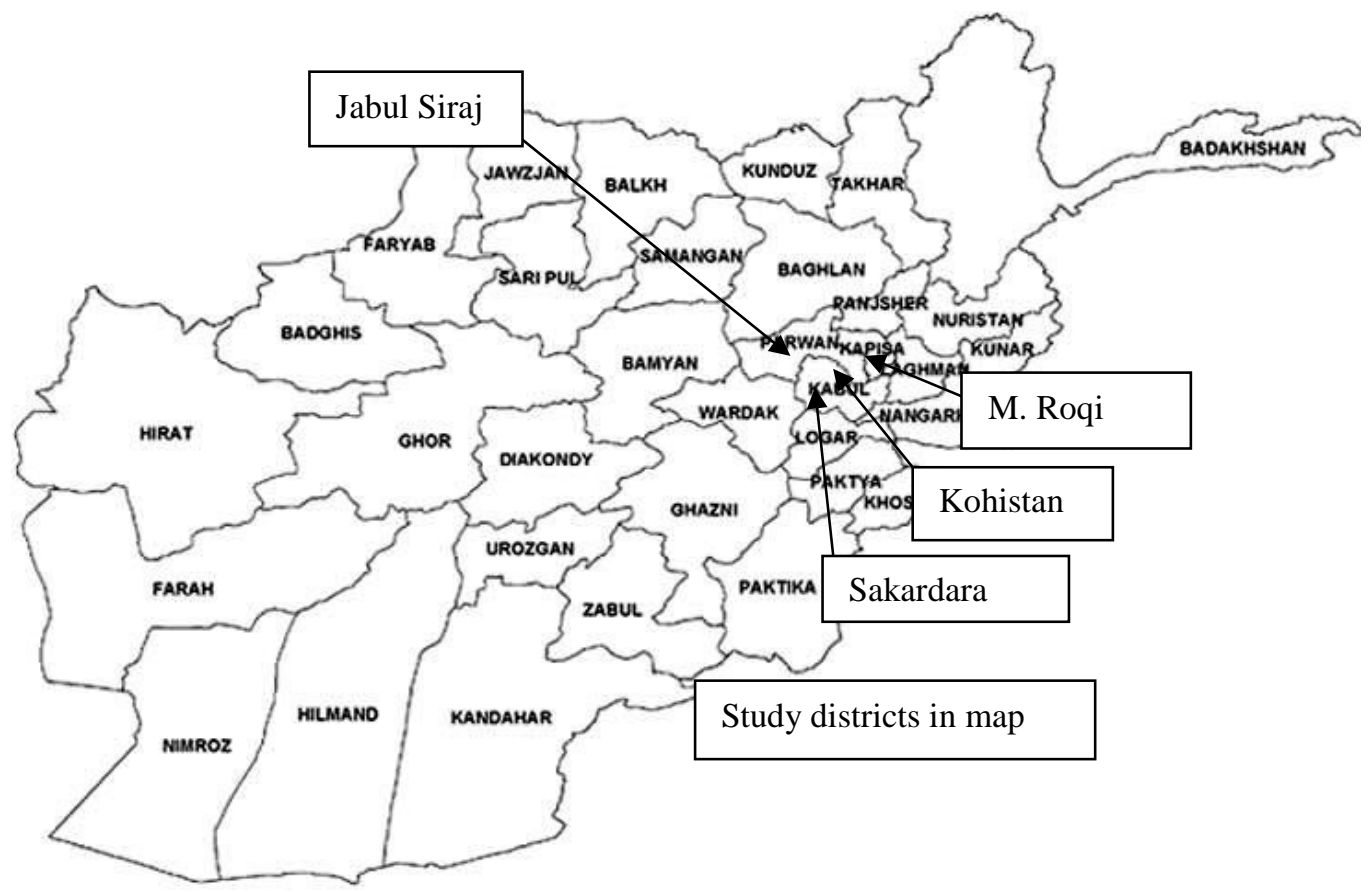

Sixteen girls received 6-day intensive training of trainers (TOT) on better nutrition practices and vegetable cultivation mechanism and they provided 3-day training to 184 girls. The project managed to lease about 9 acres (locally known as $22.5 \mathrm{Jerib}$ ) of land - on average 1.12 acres per ARCs - near these centres for the girls to do the collective gardening and they were also provided all sorts of agricultural inputs along with the installation of the greenhouses for winter cultivation. 


\subsection{Sample, tools and techniques}

Sixteen ARCs were selected from 40 ARCs given that the selected ARCs could fulfil the necessary requirements of the project as mentioned earlier. Afterwards, additional data regarding the province, districts, villages, distance of the villages, number of girls in ARC, common characteristics of the ARCs including the willingness of the adolescent girls' participation in the project were collected for conducting randomization process through pair matching of the ARCs. This was done with the help of STATA software to differentiate the treatment and control ARCs. Thus 8 ARCs of the 16 were selected as treatment and the rest as control. Each of the ARCs had 25 adolescent girls as per the project design and thus total sample for the study was 400 adolescent girls of 16 ARCs. In other words, all of them were by design selected as respondents for quantitative data collection. On the other hand, 16 focus group discussions (FGD) and the similar number of In-depth Interviews (IDI) were carried out to comprehend the perceptions of the participants, parents and community people towards girls participation in vegetables cultivation, prospects and constraints, local dynamics of vegetable consumption and the potential feasibility of the intervention including challenges under the qualitative method. The FGDs and IDIs included the adolescent girls, women and male as the participants in the discussion and as respondents. Besides, five Case Studies were collected to understand the vegetables consumption pattern of the adolescent girls' family.

\subsection{Characteristics of the samples}

The adolescent interviewed both in treatment and control ARCs mostly belong to Tajik ethnic group (99\%). The average family size of them reconfirms the national survey data, meaning 8 per household. A little more than half of the household members were female and their average age was 21 (Table 1). The education level of them was very low, which also reconfirms the existing literature (average 5 years of schooling) of this country. Interestingly $63 \%$ of them reported to have capacity about how to read and write. The unmarried people in the households were higher (72\%) compared to other categories because more than half of them were school going pupils (54\%) and there were some disable household members as well and similar proportion of them belong to the group of unpaid labour and the rest were neither paid or unpaid group. A small number of the household members were reported to have engaged with farming.

\section{Table 1: Household socio-demographic traits \%}

\begin{tabular}{lcccc}
\hline Variables & $\begin{array}{c}\text { Treatment } \\
(\mathbf{n = 1 4 8 9})\end{array}$ & $\begin{array}{c}\text { Control } \\
(\mathbf{n = 1 6 8 5})\end{array}$ & $\begin{array}{c}\text { All } \\
(\mathbf{n = 3 1 7 4})\end{array}$ & P value \\
\hline Sex: female & 51.26 & 54.91 & 53.1 & 0.040 \\
Average age & 21.35 & 21.19 & 21.27 & 0.774 \\
Average years of schooling & 5.33 & 5.02 & 5.18 & 0.057 \\
Education & & & & \\
Illiterate & 29.36 & 26.74 & 28.1 & 0.114 \\
Grade 1 to 5 & 27.39 & 34.11 & 30.7 & 0.000 \\
Grade 6 to 9 & 19.19 & 20.53 & 19.9 & 0.361 \\
Grade 10 to above & 24.07 & 18.62 & 21.4 & 0.000 \\
Can read and write & 62.37 & 62.89 & 62.6 & 0.762 \\
Marital status & & & & \\
Married & 27.21 & 28.04 & 27.6 & 0.597 \\
Unmarried & 72.10 & 71.07 & 71.6 & 0.521 \\
Widow & 0.69 & 0.82 & 0.8 & 0.689 \\
Occupation & & & & \\
Service & 8.58 & 5.85 & 7.2 & 0.005 \\
Business & 4.65 & 3.27 & 4.0 & 0.060 \\
Farming & 7.22 & 6.41 & 6.8 & 0.388 \\
Students & 51.56 & 56.13 & 53.9 & 0.017 \\
Housewife & 18.03 & 20.82 & 19.4 & 0.060 \\
Others & 9.87 & 7.52 & 8.7 & 0.026 \\
\hline
\end{tabular}




\begin{tabular}{lcccc}
\hline Paid labour & 0.81 & 0.41 & 0.6 & 0.160 \\
Unpaid labour & 50.03 & 66.37 & 58.2 & 0.000 \\
Does not have job & 49.15 & 33.22 & 41.2 & 0.000 \\
Disability & 0.76 & 0.69 & 0.7 & 0.827 \\
\hline
\end{tabular}

On the other hand, the interviewed adolescents' membership length with ARC was on average 10 months and none of them received any agriculture training earlier. Their average years of schooling was very low, meaning 2.44 years (minimum 0 and maximum 14 grade) and there is no statistically significant difference between participant and non-participants adolescents in this regards. But almost all of them (91\%) reported to have known how to read and write. In terms of grade most of them $(60 \%)$ reported to have completed grade 1 to 5 . However, overwhelming number of them reported unmarried.

\subsection{Data analysis}

Quantitative data analysis were done using SPSS while qualitative data was grouped based on similarities and differences of the indicators of the relevant themes. The qualitative data supplemented the quantitative analysis with a specific rationalization. The overall findings demonstrated the comparison between the participants and non-participants under both baseline and endline in the project.

Changes in knowledge level of the adolescent girls on the nutrition and other relevant issues related to nutrition were determined through measuring scores. Girls were asked 18 questions and each of them was given value 1 for correct answer while 0 for wrong answer. All those correct answers were summed for individual respondent and then categorized the scores on the basis of the frequencies including the average scores obtained by the respondents. Higher the scores meant the level of knowledge of the adolescents increased and vice-versa.

Changes of knowledge and participation in vegetables cultivation were also measured through difference in difference (diff-in-diff) estimate method. And consumption pattern of the vegetables was analysed by looking at the food intake pattern along with vegetables for the last 3 days since the interview date.

\section{RESULTS}

The feasibility of the pilot was assessed in terms of changing knowledge of the participants including family members, their participation in vegetables cultivation and perceptions towards girls' involvement followed by consumption and cost benefit analysis of the cultivation.

\subsection{Changes in adolescent girls' knowledge level}

One of the salient objectives of the intervention was to enhance the knowledge about the importance of vegetable intake and to reinforce vegetable consumption. After one and half year intervention the noticeable enhancement of the girls' knowledge about vitamin A and its causes of deficiency, anemia, iron deficiency and its impact on children and pregnant women, amount of food intake during adolescent, cause of night blindness and naming the nutrition sensitive vegetables was observed (Table 2). Difference in difference estimate demonstrates the knowledge scores of girls as categorized 5 to 9 increased by 20 percentage points after the intervention. Besides, the average knowledge scores was found 2 times higher in the endline compared to baseline. In regard to the knowledge enhancement a study participant being interviewed mentioned, "Prior to intervention I did not know anything about the importance of vegetables consumption and what sorts of nutritious values contain in various types of vegetables. But after being participated in the programme I now know which vegetables are good for health. For example, spinach is good for blood and stomach. Squash decreases blood pressure. Pea and bean, mint, cabbage and lettuce are sources of vitamin $C$ and has lot of protein and iron." 
Table 2: Changes in knowledge level of the adolescent girls \%

\begin{tabular}{lccccccc}
\hline Score* & Treatment & $\begin{array}{c}\text { Baseline } \\
\text { Control }\end{array}$ & P value & Treatment & $\begin{array}{c}\text { Endline } \\
\text { Control }\end{array}$ & P value & Diff in Diff \\
\hline 0 & 51 & 53 & 0.690 & 4.5 & 16.0 & 0.000 & -0.095 \\
1 to 4 & 42.5 & 46.5 & 0.422 & 56.5 & 76.5 & 0.000 & $-0.160^{*}$ \\
5 to 9 & 6.5 & 0.50 & 0.001 & 33.5 & 7.5 & 0.000 & $0.200^{* * *}$ \\
$10+$ & 00 & 00 & - & 5.5 & 00 & 0.001 & $0.055^{* *}$ \\
Mean & 0.97 & 0.79 & 0.148 & 4.4 & 2.1 & 0.000 & $2.11^{* * *}$ \\
\hline
\end{tabular}

*Minimum 0 and maximum $18, * * * \mathrm{p}<.000, * * \mathrm{p}<.001 * \mathrm{p}<.01$

Though overall girls' knowledge improved there were some issues about which the level of their knowledge was not better as expected. The reasons included lack of sharing information which were supposed to be trickled down to the girls who were not regular in the hands on training including ARC class. Besides, illiteracy or low level of education might have been responsible for low average knowledge scores. Some of the girls scoring low had low self-esteem as well. On the other hand, the reason of higher knowledge level after the intervention was access to different sources including better training being provided by the project. A study participant said, "We enhance our knowledge about vegetable cultivation, consumption and nutrition from the project. Besides, we also acquire knowledge by listening to radio, watching television and from school".

\subsection{Changes in participation, perception and vegetables consumption}

Despite of the negative attitudes of the family and community towards adolescent girls' involvement in this project as experienced at the beginning cultivating variety of vegetables collectively was a new experience for them. After being received knowledge on planting, preparing land, irrigation, protection of crops using fertilizers and pesticides, almost all of the girls in treatment areas participated in agricultural activities, particularly in vegetable cultivation, meaning that the participation increased by 38 percentage points in treatment areas compared to control areas after the intervention (Table 3). Different vegetables such as green been, pumpkin, potato, chili, squash, tomato, radish, cabbage, cauliflower, onion, and coriander were cultivated by them collectively.

Vegetables cultivation in winter season was another new experience for the girls as the project installed sheds (green houses) for this as there is usually heavy snowfall in the winter which hinders the vegetables cultivation. Girls being received additional knowledge cultivated variety of vegetables such as tomato, cucumber, pepper, cabbage, lettuce, spinach, and cauliflower in the green house. One of the mothers in Kabul said in this regard, "Girls have learned many new things through this project such as cultivation in green house. They now know what, how, where and when to cultivate vegetables and its usefulness of consumption particularly to enhance nutrition level. Also, they have utilized their knowledge in cultivating of different types of vegetables."

Referring the benefits of participation in vegetable cultivation a participant mentioned how the perceptions towards girls engagement changed. She uttered, "My father did not allow me to attend in agricultural activities at field earlier. But his behaviour has changed when he realises the benefits of her attending the vegetable cultivation. He mentioned that girl should work outside home to improve their capability and efficiency and stand on their own feet. If all people let girls participate in cultivation we trust that they are capable of doing this work." 
Table 3: Changes in girls' participation in vegetables cultivation

\begin{tabular}{lccccccc}
\hline $\begin{array}{l}\text { Participation in } \\
\text { cultivation }\end{array}$ & T & $\begin{array}{c}\text { Baseline } \\
\text { C }\end{array}$ & P value & T & C & $\begin{array}{c}\text { Endline } \\
\text { P value }\end{array}$ & Diff in Diff \\
\hline Participate (Yes) & 65.5 & 70.5 & 0.285 & 99.4 & 65.8 & 0.000 & $0.387^{* * *}$ \\
Kind of activities & & & & & & & \\
Help & 9.1 & 9.9 & 0.830 & 16.2 & 14.5 & 0.676 & 0.025 \\
Clean & 86.2 & 86.5 & 0.949 & 78.0 & 67.1 & 0.030 & $0.111^{*}$ \\
Harvesting & 0.76 & 3.5 & 0.119 & 5.7 & 15.2 & 0.004 & $-0.067^{*}$ \\
Barrier (yes) & 13.1 & 9.8 & 0.338 & 3.1 & 9.5 & 0.009 & $-0.097^{*}$ \\
Sometimes & 2.9 & 4.4 & 0.491 & 13.5 & 12.0 & 0.662 & 0.029 \\
Why don't cultivate & & & & & & & \\
Don't have land & 60.0 & 58.8 & 0.899 & 72.7 & 56.9 & 0.323 & 0.146 \\
Don't know & 23.0 & 41.1 & 0.037 & 27.2 & 43.0 & 0.323 & 0.023 \\
No one grow & 12.3 & 00 & 0.009 & 00 & 00 & - & $-0.123^{*}$ \\
\hline
\end{tabular}

$\mathrm{T}=$ Treatment, $\mathrm{C}=$ Control, $* * * \mathrm{p}<.000, * \mathrm{p}<.02$

So, collective cultivation brought a lot of changes in peoples' belief and attitudes as well. However, few of the girls did not participate in the cultivation because of barriers they faced from their family, though barriers were reported to have decreased at endline compared to baseline as shown in difference in difference estimate. One of the important barriers was the entrenched belief of male members of the family especially father and brother, who would like girls to abide by the existing norms and culture for the participation in collective cultivation. The norms and beliefs demonstrate adolescents and women were not allowed to be engaged in cultivation and should not work outside of home. Group of males in the discussion stated in this regard, "People don't like adolescent girls to be involved in any activities that are outside home, according to religion, as there might have a chance to happen something bad that will tarnish the family's prestige. This has also lot of future consequences. The family will face challenges to get girls married off. Also, if they work outside home then who will look after children and take care of household activities throughout the day."

Apart from increasing the participation of adolescent girls in vegetables cultivation enhancing the consumption of those vegetables being cultivated was one of the major focus of this project as well. Following a year end evaluation of the intervention the report reveals that though the message about the importance of consumption was reached to the adolescent girls and their family members including the community a little increase in the consumption was observed after the intervention. This result was confirmed by the interpretation of the case studies collected. The cases being collected through self-reported information from poor, middle and rich family on the last three days vegetable consumption clearly indicate that vegetables such as potato, tomato and beans were eaten but the amount was not so much. Family members reported to have eaten very simple and little amount of vegetables with common Afghan naan (flour bread) in the morning, at lunch and in the dinner. Vegetables were consumed less because of disliking by the people as reported by many of the respondents. A participant said in this regard, "I know some families that though they have good economic condition they don't consume vegetables such as okra, pumpkin and turnip. She also said that people who are not habituated with vegetables for ages will take time to change such habit."

\subsection{Cost-benefit analysis}

The project had USD 9768 fixed and USD 2192 variable cost for both summer and winter seasons cultivation. Labour cost was not included in the production as girls themselves worked in the field. ${ }^{1}$ However, from this investment, all ARCs produced a good amount of vegetables in summer season, i.e., $2060 \mathrm{Kg}$ that cost almost USD 5662.4 based on the market price available on that time. Each ARC girls could have earned a reasonable amount of money if they sold those vegetables in the market, instead of consumption, though few of them sold in the market. On the other hand, during

\footnotetext{
${ }^{1}$ However, from opportunity cost perspective, we can impute costs using 0.55 cents per person per day.
} 
winter season compared to summer a less amount of vegetables were possible to be grown in the green house as the size of it was only 10 metre wide and 12 metre long. In the green house, though there was heavy snowfall, girls cultivated tomato, cucumber, pepper, cabbage, lettuce, spinach, and cauliflower that summed up around $594 \mathrm{Kg}$, which might value USD 2000.

The production was satisfactory in summer season compared to the cost incurred. So, analysis demonstrates the financial viability of the project, though the case was different in winter season. The cost in winter season was high as there was greenhouse installation cost. But the benefit was that this green house would be possible to be used for long time for example 10 to 15 years as it was made by iron. In the next winter season this would be used for cultivation without any significant cost, except the seeds and fertiliser cost. Besides, the green house was the most attractive not only for the girls but also to parents and community as this was the innovative approach for the girls and they could work inside the green house without having the visibility of the outsider - male in particular. Therefore, girls being experienced cultivating vegetable inside the greenhouses for the first time during winter was much appreciated by the community. A mother mentioned, "The good thing with greenhouses was that it was very safe for the girls as it is not open. It's being installed within the community. Their parents will send them without any tension."

\section{DISCUSSION}

Within the purview of war-savaged, highly conservative and male-dominated society adolescents girls are strongly discouraged to be involved in collective vegetable cultivation. It is a stigma in the society when afghan girls are exposed to men for working outside home. Therefore, adolescent girls didn't show interest and parents also did not allow their daughters to participate in this project at its initial stage. Instead, training on tailoring, embroidery and carpet weaving which would be possible in staying inside of their homes was preferred. But once being convinced through motivation and mobilization as to the necessity and the importance of vegetable cultivation and consumption their mind set changed and they were allowed to participate in the project. Besides, both girls and their parents including community gained more confidence when the knowledge being achieved was shared among them. Also, knowledge was spilled over to the neighbour. Thus, the project was effective in enhancing knowledge of the participants including parents and community people that would sustain even after the intervention.

The assessment also reveals the knowledge gained instigated the girls to engage in variety of vegetables cultivation. In other words, prior to intervention few vegetables were cultivated in limited scale particularly in summer season. But after initiation of the project, cultivation of vegetables such as pumpkin, green bean, ladies finger, squash, cabbage, potato, tomato, radish, spinach and cauliflower increased.

Increased vegetable cultivation assumed to leading higher consumption but it did happen a little as it depended on norms of eating vegetables in the study areas. Culturally, people in the study areas were found reluctant to consume vegetables more because of their food habit. However, the importance of vegetables consumption to enhance the nutrition level was comprehended after the intervention but changing habit of vegetable intake might take time, as it was reported.

Alongside the benefit of vegetables consumption there were much more opportunities of financial gain of the girls in this project. The evaluation reveals that with the amount of vegetables harvested against the cost incurred girls could have earned a reasonable amount of money through selling vegetables in the market. Thus, the financial gain as being created by the project was reported to have enhanced the girls' voice within the family and also generated the potentials of reducing the level of their marginalization. Besides, with ensuring the adolescent girls' involvement in vegetables cultivation the project played significant role in challenging the local tradition and changing the embedded beliefs and practices of the family and community people related to gender relations. 
The evaluation explicitly reveals that collective vegetables cultivation by adolescent girls created the opportunity of increasing dietary diversity in their households that would lead to enhance the nutritional outcomes as Pandey et al. (2016) found the similar results in their evaluation. Evans et al. (2012) also reported that garden based programs are promising avenue for increasing fruit and vegetables consumption for school age children while Fulford and Thompson (2013) found in their study that youth community development programming could be effective strategy of youth empowerment as it brought many positive changes such as skill building, self-esteem, improved nutrition and food security.

Despite of its feasibility there were potential challenges that need to be carefully addressed in scaling up the pilot and for sustainability. While working in the field girls might have faced the potential threat of harassment that especially include the bad comments being passed by the boys and arms group might hinder the girls' participation in cultivation as they don't like, though girls did not experience such kind of challenge during the project period.

During the winter season heavy snowfall restrains from growing vegetables. Providing knowledge to build traditional greenhouse available in some areas could be alternative for the girls to continue cultivation in the winter season. Lack of access to improved technology, knowledge and attitudes towards girls participation were reported as barrier. Knowledge needs to be given by the government agriculture extension workers and should inspire to use local variety of seeds and locally made fertiliser in order to be feasible and simultaneously mobilization programmes to the community to change the entrenched attitudes for allowing girls to participate in cultivation need to continued.

\section{CONCLUDING REMARKS}

The study reveals that despite of the challenges vegetables gardening by the girls to contribute in addressing the malnutrition and to reduce their level of marginalization could be effective strategy throughout the country like Afghanistan. However, this feasibility assessment instigated further research in order to get more credible impact of the intervention. Such research could facilitate substantial outcomes for designing the nutrition sensitive agriculture programme in a large scale.

\footnotetext{
Funding: The study was financially supported by the Department for International Development (DFID), UK through the coordination of Institute of Development Studies (IDS), Sussex and MSSRF, India.

Competing Interests: No conflict of interest was reported by the authors.

Contributors/Acknowledgement: The authors are absolutely indebted to Dr. Alan Dangour, Professor in Food and Nutrition for Global Health at the London School of Hygiene and Tropical Medicine, UK and lead researcher of Leveraging Agriculture and Nutrition for South Asia (LANSA) Responsive Window Call II for his invaluable suggestions and guidance and thanks him for inspiration to put in writing this article. Also special thanks to Dr. Munshi Sulaiman for his valuable directions and supports in conducting the study. And Murtaza Haidary, Muzdha Ghulam, Zakirullah Stanikzai and Leema Naderi for being supported in different research steps, thanks to them as well. The authors are also grateful to Department for International Development (DFID), UK and M.S. Swaminathon Research Foundation, India for funding and coordinating the project.

Views and opinions expressed in this study are the views and opinions of the authors, Asian Journal of Agriculture and Rural Development shall not be responsible or answerable for any loss, damage or liability etc. caused in relation to/arising out of the use of the content.
} 


\section{References}

Evans, C. E., Christian, M. S., Cleghorn, C. L., Greenwood, D. C., \& Cade, J. E. (2012). Systematic review and meta analysis of school based interventions to improve daily fruit and vegetables intake in children aged 5 to 12 years. American Journal of Clinical Nutrition, 96(4), 889-901. view at Google scholar / view at publisher

Fulford, S., \& Thompson, S. (2013). Youth gardening programming as community development: the youth of eco-action in Winnipeg, Canada. Canadian Journal of Non-profit and Social Economy Research, 4(2), 56-75. view at Google scholar

Holmes, R., \& Jones, N. (2009). Gender inequality, risk and vulnerability in the rural economy: Fefocusing the public works agenda to take account of economic and social risks. Background of Report for SOFA. view at Google scholar

LANSA (2017). Afghanistan evidence review: agriculture and nutrition linkage. http:lansasouthasia.org/Lansa/sites/default/files/Afghanistan Evidence Review Agriculture and Nutrition Linkage. Accessed 10 December 2017.

National Nutrition Survey Afghanistan (2013). Ministry of public health (MoPH). Central Statistics Organization (CSO) and UNICEF.

National Risk and Vulnerability Assessment (2011-12). Analysis based on the national risk and vulnerability assessment of 2007/08. The world bank and ministry of economy, Islamic republic of Afghanistan. http://www.fao.org/fileadmin/user_upload/emergencies/docs/CAP2011_Afghanistan.pdf. Accessed 30 November 2017.

Pandey, V. L., Dev, S. M., \& Jayachandran, U. (2016). Impact of agricultural interventions on the nutritional status in South Asia: A review. Food Policy, 62, 28-40. view at Google scholar 1 view at publisher

Ruel, M. T., \& Alderman, H. (2013). Nutrition-sensitive interventions and programmes: how can they help to accelerate progress in improving maternal and child nutrition?. Lancet, 382(9891), 536-551. view at Google scholar / view at publisher

Sen, B., Menon, P., Ahmed, A. U., \& Chowdhury, F. P. (2010). Food utilization and nutrition security. Bangladesh food security investment forum; Dhaka. view at Google scholar 